\title{
A PESGA DE LAGOSTAS NA PLATAFORMA CONTINENTAL AMAZÔNICA
}

\section{The lobster fishing on the Amazonian Continental Shelf}

\author{
Francisco José da Silva Santos ${ }^{1}$, Kátia Cristina de Araújo Silva², Bianca Bentes ${ }^{3}$, \\ Maria Eduarda Garcia de Sousa Pereira ${ }^{4}$, Alex Garcia Cavalleiro de Macedo Klautau ${ }^{5}$, \\ Israel Hidenburgo Aniceto Cintra6*
}

\footnotetext{
${ }^{1}$ Mestrando do Programa de Pós-Graduação em Aquicultura e Recursos Aquáticos Tropicais, Instituto Socioambiental e dos Recursos Hídricos, Universidade Federal Rural da Amazônia. E-mail: franzesantos@hotmail.com ${ }^{2}$ Professora do Instituto Socioambiental e dos Recursos Hídricos, Universidade Federal Rural da Amazônia. E-amail: kcasilva@hotmail.com

${ }^{3}$ Professora do Instituto de Estudos Costeiros, Universidade Federal do Pará. E-mail: biancaa@ufpa.br ${ }^{4}$ Professora do Instituto Federal do Pará (Campus Cametá). E-mail: eduardapesca@yahoo.com.br ${ }^{5}$ Analista Ambiental do Centro de Conservação da Biodiversidade Marinha do Norte, Instituto Chico Mendes de Conservação da Biodiversidade. E-mail: alex.klautau@icmbio.gov.br

${ }^{6}$ Professor do Instituto Socioambiental e dos Recursos Hídricos, Universidade Federal Rural da Amazônia. E-mail: israelcintra@hotmail.com

*Autor para correspondência: israelcintra@hotmail.com
}

\begin{abstract}
RESUMO
A exploração de lagostas no Brasil, desde a década de 1960, destaca-se como um dos principais itens da balança comercial. O estudo descreve a pesca de lagostas realizada na Plataforma Continental Amazônica. Os dados foram coletados no período de agosto de 2014 a novembro de 2015. Na costa norte do Brasil, apenas embarcações artesanais atuam na pesca e utilizam a caçoeira como apetrecho. As embarcações são denominadas de "universais", pois também atuam em outras pescarias. Observou-se a ocorrência de três espécies de lagostas com importância comercial: Panulirus meripurpuratus (Giraldes \& Smyth, 2016), Parribacus antarcticus (Lund, 1793) e Scyllarides delfosi (Holthuis, 1960). Na rotina de bordo, ficaram nítidos a falta de higienização das estruturas e o inadequado manuseio durante as pescarias. Quanto aos aspectos legais, observa-se um cenário preocupante, despontando, entre vários fatores, o número de embarcações, a permissão de pesca e o uso de apetrecho de pesca ilegal. A área de atuação da frota está se deslocando para o norte, sendo, possivelmente, motivada pela busca de novos locais de pesca e pela rivalidade entre as frotas lagosteira e pargueira que compartilham a mesma área de pesca.
\end{abstract}

Palavras-chave: costa norte, pesca artesanal, biodiversidade.

Recebido em: 30/4/2019

Aprovado em: 22/11/2019

Publicado online em: $20 / 3 / 2020$ 


\begin{abstract}
The exploitation of lobsters in Brazil, since the 1960's, stands out as one of the main items of the trade balance. The study describes the lobster fishing carried out in the Amazon Continental Shelf. The data were collected from August 2014 to November 2015. On the northern coast of Brazil, only artisanal vessels operate in fishing and use the "caçoeira" net as fishing tackle. The vessels are called "universal" because they also work in other fisheries. Three species of lobsters with commercial importance were observed: Panulirus meripurpuratus (Giraldes $\mathcal{E}$ Smyth, 2016), Parribacus antarcticus (Lund, 1793) and Scyllarides delfosi (Holthuis, 1960). In the on-board routine, it was clear the lack of hygiene of the structures and inadequate handling during fishing. Regarding the legal aspects, there is a worrying scenario, highlighting, among several factors, the number of vessels, the fishing license and the use of illegal fishing gear. The fleet area of action is moving to the north, which is possibly motivated by the search for new fishing spots and the rivalry between lobster fleet and red snapper fleet that share the same fishing area.
\end{abstract}

Keywords: north coast, artisanal fishing, biodiversity.

\title{
INTRODUÇÃO
}

A exploração da lagosta, desde a década de 1960, destaca-se como um importante recurso pesqueiro no Brasil, ocorrendo pesca comercial do estado do Amapá até o estado do Espírito Santo, gerando em todo país emprego e renda.

As lagostas capturadas no Brasil atendem ao mercado nacional e internacional e seus principais importadores são os Estados Unidos, o Japão e alguns países da Europa, como Holanda, Portugal e França (Brasil, 2012). Historicamente, a atividade é voltada, principalmente, para o mercado externo, e as exportações anuais giram em torno de 2.500 t de cauda, o que corresponde ao ingresso de divisas da ordem de 50 a 90 milhões de dólares (Aragão, 2010).

A pesca da lagosta apresentou, nos anos de 1991 a 2001, sensíveis flutuações na produção, crescimento acentuado do esforço de pesca e diminuição da produtividade, demonstrando que em uma parte do litoral dos estados do Ceará, Rio Grande do Norte e Pernambuco os estoques encontram-se em elevado grau de esgotamento; enquanto nos estados do Pará/Amapá e Espírito Santo/Bahia, os estoques apresentam-se em situação mais satisfatória (Oliveira, 2005). Aragão e Cintra (2018), ao analisarem o rendimento das pescarias de lagosta na costa brasileira, no período de 2005 a 2015, verificaram que as capturas oscilaram ao longo dos anos, com alguns picos de produção importantes, apresentando, de maneira geral, tendência decrescente.

Na costa norte do Brasil, a exploração comercial de lagosta teve início em meados da década de 1990, com valores de produção baixos até 1998, quando atingiu um patamar da ordem de 126,2 t, e, em 1999, chegou a 640 t (Ibama, 2008). Dados da estatística da pesca nacional mostram que em 2006 o Pará desembarcou 1.427 t de lagosta, correspondendo a $21 \%$ da produção brasileira, ficando atrás apenas do Ceará, que desembarcou naquele ano 1.907,5 t (Ibama, 2008). Os resultados indicam que, apesar das elevadas taxas de mortalidade por pesca e do comprometimento da estrutura por idade/comprimento da população, o estoque apresenta certa estabilidade quanto à sua composição em número e biomassa (Aragão \& Cintra, 2018). 
No Brasil, a frota lagosteira explora comercialmente espécies das famílias Palinuridae Latreille, 1802, e Scyllaridae Latreille, 1825, respectivamente, Panulirus meripurpuratus (Giraldes \& Smyth, 2016), Panulirus laevicauda (Latreille, 1817), Panulirus echinatus (Smith, 1869) e Scyllarides brasiliensis (Rathbun, 1906) e Scyllarides delfosi (Holthuis, 1960) (Silva et al., 2013). Por meio de análise genética, Giraldes e Smyth (2016) dividiram Panulirus argus em duas espécies no oceano Atlântico, ficando a biogeografia de Panulirus argus (Latreille, 1804) em águas americanas e no mar do Caribe e Panulirus meripupuratus (Giraldes \& Smyth, 2016) em águas brasileiras.

Na plataforma continental da costa norte do Brasil ocorrem 10 espécies de lagostas: Acanthacaris caeca A. (Milne-Edwards, 1881), Nephropsis aculeata (Smith, 1881), Nephropsis rosea (Spence Bate, 1888), Palinustus truncatus A. (Milne-Edwards, 1880), Panulirus meripurpuratus (Giraldes \& Smyth, 2016), Parribacus antarcticus (Lund, 1793), Polycheles typhlops (Heller, 1862), Scyllarides delfosi (Holthuis, 1960), Stereomastis sculpta (Smith, 1880) (Silva et al., 2013) e Scyllarus chacei (Holthuis, 1960) (Silva et al., 2012). Na região Norte são exploradas comercialmente P. meripurpuratus (92\%) e S. delfosi (8\%) (Porto; Cintra \& Silva, 2005).

A Plataforma Continental Amazônica brasileira estende-se da Ponta do Tubarão, no Maranhão $\left(4^{\circ} \mathrm{S}, 43^{\circ} \mathrm{W}\right)$, até o Cabo Orange, no Amapá $\left(5^{\circ} \mathrm{N}, 51^{\circ} \mathrm{W}\right)$, com cerca de $2.250 \mathrm{~km}$ de extensão, excluindo as reentrâncias do litoral a ilhas (Floriani; Fukuda \& Pinto, 2004). Nessa região, a precipitação é elevada e constante (mais de $1.500 \mathrm{~mm} / \mathrm{ano}$ ) e as temperaturas são altas (maiores de $20^{\circ} \mathrm{C}$ ) e com baixa variação térmica (Nittrouer et al., 1995).

Na Plataforma Continental Amazônica, os principais bancos lagosteiros estendem-se do Pará ao Amapá. No Amapá, situam-se em profundidades entre 80 m e 100 m, com fundo constituído de areia, pedras e corais; no Pará, situam-se em profundidades entre 60 m e 92 m em substrato variável, ora constituído de areia, areia e pedras e corais (Porto; Cintra \& Silva, 2005).

No Pará, as lagostas são desembarcadas nos municípios de Bragança e Augusto Corrêa. Bragança, localizada a $210 \mathrm{~km}$ de Belém, é uma das cidades mais antigas do estado e importante ponto de desembarque pesqueiro, e Augusto Corrêa está localizada a $14 \mathrm{~km}$ de Bragança. Apesar de existirem áreas de pesca de lagosta ao largo da costa do Amapá, não há registros de desembarques do crustáceo nesse estado (Porto; Cintra \& Silva, 2005).

A pesca lagosteira na Plataforma Continental Amazônica é relevante e o conhecimento da situação atual da atividade na região é instrumento básico que pode subsidiar a tomada de decisões para a sustentabilidade dos estoques explorados. Este estudo fornece informações atualizadas sobre a área de pesca, a biodiversidade capturada, o procedimento de captura, o beneficiamento a bordo e o custo de produção da atividade lagosteira na costa norte do Brasil.

\section{MATERIAL E MÉTODOS}

O estudo teve como base de dados informações coletadas a bordo de embarcações lagosteiras licenciadas, nos meses de setembro de 2014, outubro e novembro de 2015, totalizando cinco embarques e 59 dias de pesca, por meio de um projeto de pesquisa executado pelo Centro de Pesquisa e Conservação da Biodiversidade do Norte (Cepnor/ ICMBio) (Tabela I). 
Também foram realizadas entrevistas com armadores, mestres e pescadores da região, por meio de questionários semiestruturados nos anos de 2014 e 2015, visitas aos locais de desembarque, registros fotográficos, levantamento de informações disponíveis na literatura especializada e visitas às sedes de empresas localizadas em Bragança/PA.

$\begin{aligned} & \text { Tabela I - Ano, mês, local de embarque/desembarque e dias de pesca amostrados } \\
& \text { na frota lagosteira sediada nos municípios de Bragança e Augusto Corrêa (Pará) } \\
& \text { que operam na Plataforma Continental Amazônica }\end{aligned}$
\begin{tabular}{cccc} 
Ano & Mês & Embarque/desembarque & Dias de coleta a bordo \\
\hline 2014 & Setembro & Augusto Corrêa & 15 \\
2014 & Setembro & Bragança & 10 \\
2015 & Outubro & Augusto Corrêa & 3 \\
2015 & Outubro & Augusto Corrêa & 6 \\
2015 & Novembro & Augusto Corrêa & 25 \\
\hline Total & & & 59
\end{tabular}

As principais informações coletadas a bordo foram: área de pesca, caracterização do apetrecho de pesca, caracterização das embarcações, rotina da faina a bordo, equipamentos e materiais usados nas operações de pesca, procedimentos de captura adotados pelos mestres (comandantes), no que se refere à escolha do local, processamento a bordo, aspectos legais da atividade e análise da diversidade de espécies capturadas, tendo como base a observação de aspectos físicos, econômicos e ambientais existentes.

Os espécimes capturados foram identificados até o nível de espécie quando possível. A biodiversidade acompanhante, cuja identificação não foi possível de ser realizada a bordo, foi transportada para análise no Laboratório de Crustáceos do Centro de Conservação da Biodiversidade Marinha do Norte (Cepnor/UFRA). A identificação da ictiofauna foi baseada nas literaturas de Figueiredo e Menezes (1979, 1980, 2000) e Cervigón et al. (1992) em nível de espécie, entre outras literaturas.

\section{RESULTADOS}

\section{Área de pesca}

Os dados coletados apontam que a pesca da lagosta na costa norte está entre as latitudes $2^{\circ} \mathrm{N}, 47^{\circ} 30^{\prime} \mathrm{W}$ e $4^{\circ} \mathrm{N}, 49^{\circ} 30^{\prime} \mathrm{W}$, com pesqueiros situados em profundidades entre 74 m e 98 m em substrato constituído de areia, pedras e corais (Figura 1).

Os lances de pesca onde foram realizadas as capturadas de lagosta apontam uma área que concentra a frota lagosteira $\left(2^{\circ} \mathrm{N}, 47^{\prime} 42^{\prime \prime} \mathrm{W} / 01^{\circ} \mathrm{N}, 47^{\prime} 37^{\prime \prime} \mathrm{W}\right)$ (Figura 1). 
Figura 1 - Mapa com a localização da área de pesca de lagostas na Plataforma Continental Amazônica

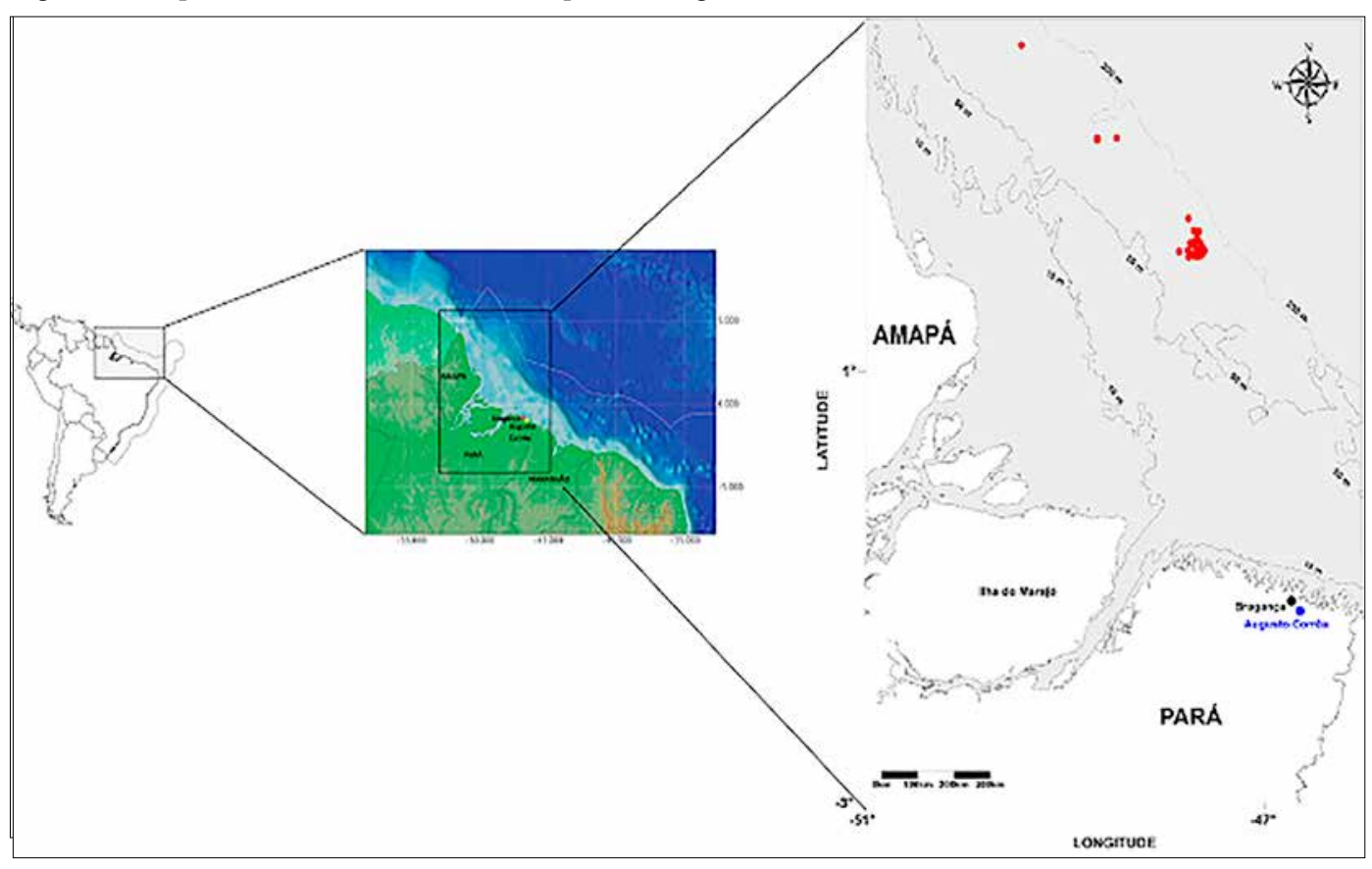

\section{Embarcações}

Existe um quantitativo de 43 embarcações atuando na pesca da lagosta na região Norte. Essas embarcações pertencem a um pequeno contingente de armadores, dotados de infraestrutura de apoio, tais como: trapiches (embarque e desembarque), galpões (armazenamento de material diverso) e câmaras frigoríficas (estocagem).

As embarcações lagosteiras que operam na costa norte podem ser classificadas como de médio porte, possuindo casco de madeira, casaria, arqueação menor de $25 \mathrm{AB}$ (Arqueação Bruta) e comprimento variando de $12 \mathrm{~m}$ a $16 \mathrm{~m}$. Essas embarcações são movidas a motor a diesel, com potência variando de 110 a $200 \mathrm{hp}$. Possuem equipamentos eletrônicos para navegação e pesca, tais como GPS, ecossonda e rádio VHF e UHF. Os equipamentos eletrônicos são indispensáveis na pesca da lagosta na costa norte, onde o GPS e a ecossonda são fundamentais, tanto na determinação da localização dos pesqueiros que ficam distantes da costa, quanto nas determinações da profundidade e tipo de fundo, que são também fundamentais para o lançamento do apetrecho de pesca.

A tripulação é composta de seis a nove integrantes, sendo subdividida de acordo com a função a bordo em mestre, motorista, geleiro/pescador e os demais classificados como pescadores, sendo comum encontrar o mestre realizando também a função de motorista.

As embarcações lagosteiras possuem autonomia de mar que varia entre 35 e 45 dias (porto a porto) e o tempo de pesca depende da produção nas pescarias, consumo de óleo e condição do gelo.

As embarcações da costa norte são conhecidas como embarcações cearenses, devido às suas características bastante singulares, sendo as preferidas entre mestres e pescadores. Essas embarcações apresentam uma excelente estabilidade, por causa de sua largura de boca, o que confere segurança à navegação. São barcos que facilmente podem ser adaptados a outros tipos de pescarias. Por esse motivo, são denominadas embarcações universais por pescadores e mestres. 


\section{Apetrecho de pesca}

As embarcações que atuam na pesca da lagosta, na Plataforma Continental Amazônica, em sua quase totalidade, utilizam a rede caçoeira como apetrecho de pesca. Essas redes podem ser confeccionadas com nylon multifilamento, material bastante oneroso, mais pesado e de difícil manejo, ou com nylon monofilamento, que é mais leve, pois tem menor altura, malhas menores com fio mais finos.

A caçoeira é um apetrecho que opera diretamente sobre o substrato, utiliza isca para atrair as lagostas e sofre influência da força das correntes. O tipo de material usado pelas embarcações pesquisadas é a rede caçoeira com panagem multifilamento trançado, sem nó, sendo a preferida dos mestres e pescadores, por ser mais resistente e possuir vida útil mais longa (Figura 2 e Tabela II).

Os componentes integrantes apresentados na Figura 2 podem sofrer alterações em suas características, tanto na quantidade de material utilizado, quanto na composição de cada material (Tabela II). Essas adaptações dependem da localização da área na qual o apetrecho vai operar.

Figura 2 - Esquema da rede caçoeira utilizada na pesca de lagostas na Plataforma Continental Amazônica, composta por: panagem $(\mathrm{P})$, calões $(\mathrm{C})$, filame $(\mathrm{F})$, boias $(\mathrm{B})$, garateias $(\mathrm{G})$, tralha de boia $(\mathrm{TB})$, tralha de chumbada (TC) e iscas (IS)

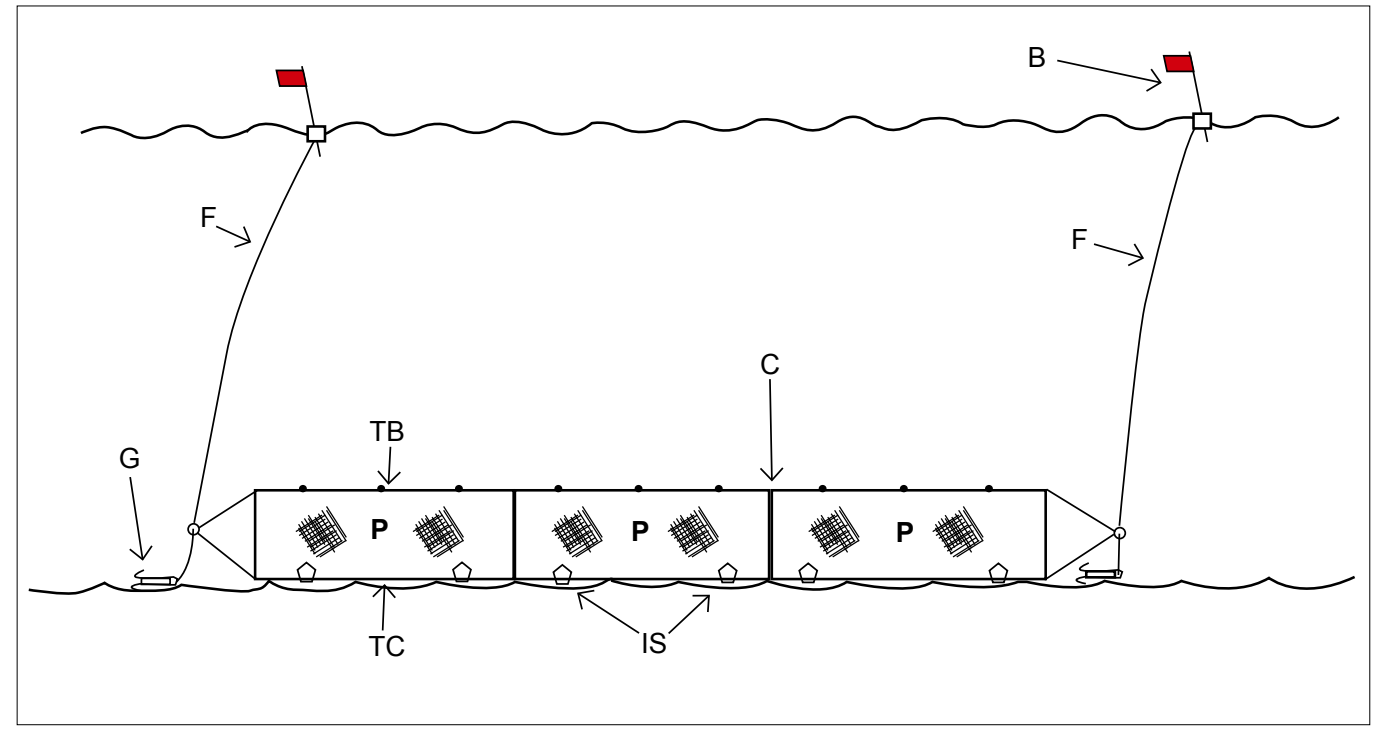

A lagosta aparece principalmente em substratos de algas calcárias; no entanto, dependendo da região, as pescarias podem ser realizadas em áreas mais próximas à costa, em águas menos profundas e por embarcações de pequeno porte, como no caso de jangadas muito comuns no Nordeste. Nesse caso, as redes de monofilamento são menos pesadas, pois têm menor altura, malhas menores de fio mais fino, sendo utilizadas por embarcações a vela que permitem operações manuais de lançamento e recolhimento. 
Tabela II - Descrição e caracterização da rede caçoeira, utilizada na pesca de lagostas da região Norte do Brasil

\begin{tabular}{|c|c|}
\hline Componente & Descrição e caracterização \\
\hline Panagem (P) & $\begin{array}{l}\text { Material confeccionado em nylon de poliamida } \\
\text { multifilamento, de cor azul, fio trançado, sem nós, } \\
\text { com tamanho de malha igual a } 12 \mathrm{~cm} \text {. Possui } 150 \mathrm{~m} \text { de } \\
\text { comprimento e } 1,90 \mathrm{~m} \text { de altura (medida entre tralhas). }\end{array}$ \\
\hline Calão (C) & $\begin{array}{l}\text { Haste de madeira com aproximadamente } 1,20 \mathrm{~m} \text { de } \\
\text { altura. São usados como estruturas de apoio às redes, } \\
\text { mantendo-as na vertical e proporcionando conformação } \\
\text { adequada durante as pescarias. }\end{array}$ \\
\hline Filame $(\mathrm{F})$ & $\begin{array}{l}\text { Cabo de polietileno trançado com } 12 \mathrm{~mm} \varnothing \text {, de cor azul. } \\
\text { Tem função de fixar a boia de sinalização à rede. }\end{array}$ \\
\hline Boias (B) & $\begin{array}{l}\text { Conjunto formado por um bloco de isopor (poliestireno) } \\
\text { de } 50 \text { x } 40 \text { x } 40 \mathrm{~cm} \text {, haste de madeira e uma bandeira de } \\
\text { cor encarnada. Tem como função servir como sinalização } \\
\text { de localização da rede. }\end{array}$ \\
\hline Tralha de boia (TB) & $\begin{array}{l}\text { Formada por dois cabos de poliamida trançados, unidos } \\
\text { a partir do entralhamento } 2 / 1 \text {, cor branca, com } 5 \mathrm{~mm} \varnothing, \\
\text { contendo flutuadores distanciados entre si a } 1,30 \mathrm{~m} \text {. }\end{array}$ \\
\hline Tralha de chumbada (TC) & $\begin{array}{l}\text { Formada por dois cabos de poliamida trançados, unidos } \\
\text { a partir do entralhamento } 2 / 1 \text {, cor branca, com } 5 \mathrm{~mm} \varnothing \text {, } \\
\text { contendo chumbadas distanciadas entre si a } 85 \mathrm{~cm} \text {. }\end{array}$ \\
\hline Garateia (G) & $\begin{array}{l}\text { Material confeccionado em metal e concreto, possuindo } \\
\text { hastes de vergalhão, em forma de âncora. Peso de } \\
\text { aproximadamente } 35 \mathrm{~kg} \text {. Possui a função de facilitar a } \\
\text { submersão da rede e sua fixação. }\end{array}$ \\
\hline Isca (IS) & $\begin{array}{l}\text { Cabeça de piramutaba Brachyplatystoma vaillantii } \\
\text { (Valenciennes, 1840). }\end{array}$ \\
\hline
\end{tabular}

\section{Procedimentos de captura}

A faina da pesca da lagosta segue um conjunto de ações que devem ser realizadas de forma sincronizada e com um grau de atenção bastante aguçado por parte dos pescadores. A operação de pesca tem início com a chegada da embarcação ao pesqueiro, a partir das coordenadas predefinidas pelo mestre da embarcação, sendo essas informações observadas com o auxílio do GPS e a verificação do perfil do fundo e profundidade correspondente com o auxílio da ecossonda.

A rotina de atividades a bordo, quantidade de redes lançadas e recolhidas, é de responsabilidade do mestre da embarcação e depende do resultado das capturas. Considerando uma quantidade ótima de lagostas capturadas, durante o primeiro lançamento, as pescarias se comportam da seguinte forma: todas as redes são lançadas e, após o tempo estipulado (por 12 horas), todas as redes são recolhidas; a esse tipo de pescaria é dado o nome de "pescaria de ida e vinda". No entanto, quando as capturas são fracas após o primeiro recolhimento, todo o material novamente é lançado, porém o recolhimento é realizado de forma parcelada, ou seja, se forem lançadas 60 redes, 30 seriam recolhidas no primeiro momento e as restantes após um período de 12 horas ou mais, sendo esse procedimento denominado "pescaria de dormida".

Determinado o local de pesca, o apetrecho é lançado ao mar seguindo uma sequência de procedimentos. A embarcação é mantida em seguimento (avante), em baixa velocidade. 
Nesse momento é lançado o cabo filame, amarrado a um bloco de isopor, contendo uma haste de madeira com uma bandeira de sinalização de cor vermelha. O comprimento do filame varia de acordo com a profundidade onde o apetrecho vai operar, sendo aconselhado esse comprimento variar de uma vez e meia a duas vezes o valor da profundidade detectada na ecossonda. Em seguida é lançada a primeira garateia, que tem como objetivo "levar" uma das extremidades da rede até o fundo e servir como primeiro ponto de fixação. O restante do material é cuidadosamente liberado, sendo essa etapa da faina finalizada com o lançamento da segunda garateia e, em seguida, o segundo filame com a boia de sinalização.

Para a realização do recolhimento do apetrecho, o mestre direciona a embarcação até uma das boias de sinalização e um pescador realiza o resgate do filame com o auxílio de uma "retinida". Este cabo é desatrelado da boia e envolto em um guincho hidráulico, que auxiliará no recolhimento da rede. $\mathrm{O}$ mestre mantém a embarcação em movimento, com baixa velocidade. Nesse momento, dois pescadores localizados na borda da embarcação puxam a rede, enquanto outro pescador organiza o cabo no convés e retira as lagostas da rede e outros dois pescadores organizam a rede e substituem as iscas. Durante o processo de recolhimento, o mestre procura não forçar o material de pesca, buscando não danificar o habitat natural, uma vez que se trata de um apetrecho que trabalha sobre o substrato.

Normalmente, devido à experiência, a maioria dos mestres lagosteiros já possui todas as localizações (latitude e longitude) referentes aos bancos pesqueiros existentes; no entanto, tal fato não dispensa a realização de observações referentes ao estado do mar e à presença de espécies marinhas que venham a prejudicar o bom andamento das pescarias. Relatos de pescadores e mestres indicaram que a presença de tuninha Pontoporia blainvillei (Gervais \& d'Orbigny, 1844) nas áreas de pesca é um fator prejudicial, o que resulta no não lançamento do material de pesca. Existem relatos de emalhes acidentais desses animais na rede de pesca, ocasionando grandes transtornos durante os trabalhos a bordo, sem contar com a atual situação do risco de extinção da espécie.

Outra espécie que também provoca transtornos às pescarias de lagostas é o cangulo Balistes vetula (Linnaeus, 1758). Os pescadores relatam que o peixe ataca as lagostas emalhadas, danificando-as e deixando-as impróprias para a comercialização.

\section{Diversidade capturada}

Durante os embarques, foram identificadas três espécies de lagostas, P. meripurpuratus, $P$. antarcticus e $S$. delfosi (Figura 3), e 30 espécies de peixes (Figura 4), além de outros organismos aquáticos não identificados, tais como siris, paguros, estrelas-do-mar, esponjas, algas, corais etc. (Figura 5). Nas pescarias, além da captura de organismos aquáticos, também ocorre a presença de parte do substrato (pedras), comprovando de forma efetiva o dano que a caçoeira provoca no habitat.

Entre as espécies capturadas, o cação-viola Pseudobatos percellens (Walbaum, 1792) e a arraia elétrica Narcine bancroftii (Griffith \& Smith, 1834) encontram-se em situação preocupante com relação ao perigo de extinção, de acordo com a lista vermelha da União Internacional para a Conservação (IUCN). 
Figura 3 - Espécies comerciais de lagostascapturadasnaPlataforma Continental Amazônica: lagosta vermelha Panulirus meripurpuratus (Giraldes \& Smyth, 2016) (A) e as lagostas sapateiras Parribacus antarcticus (Lund, 1793) (B) e Scyllarides delfosi (Holthuis, 1960) (C)
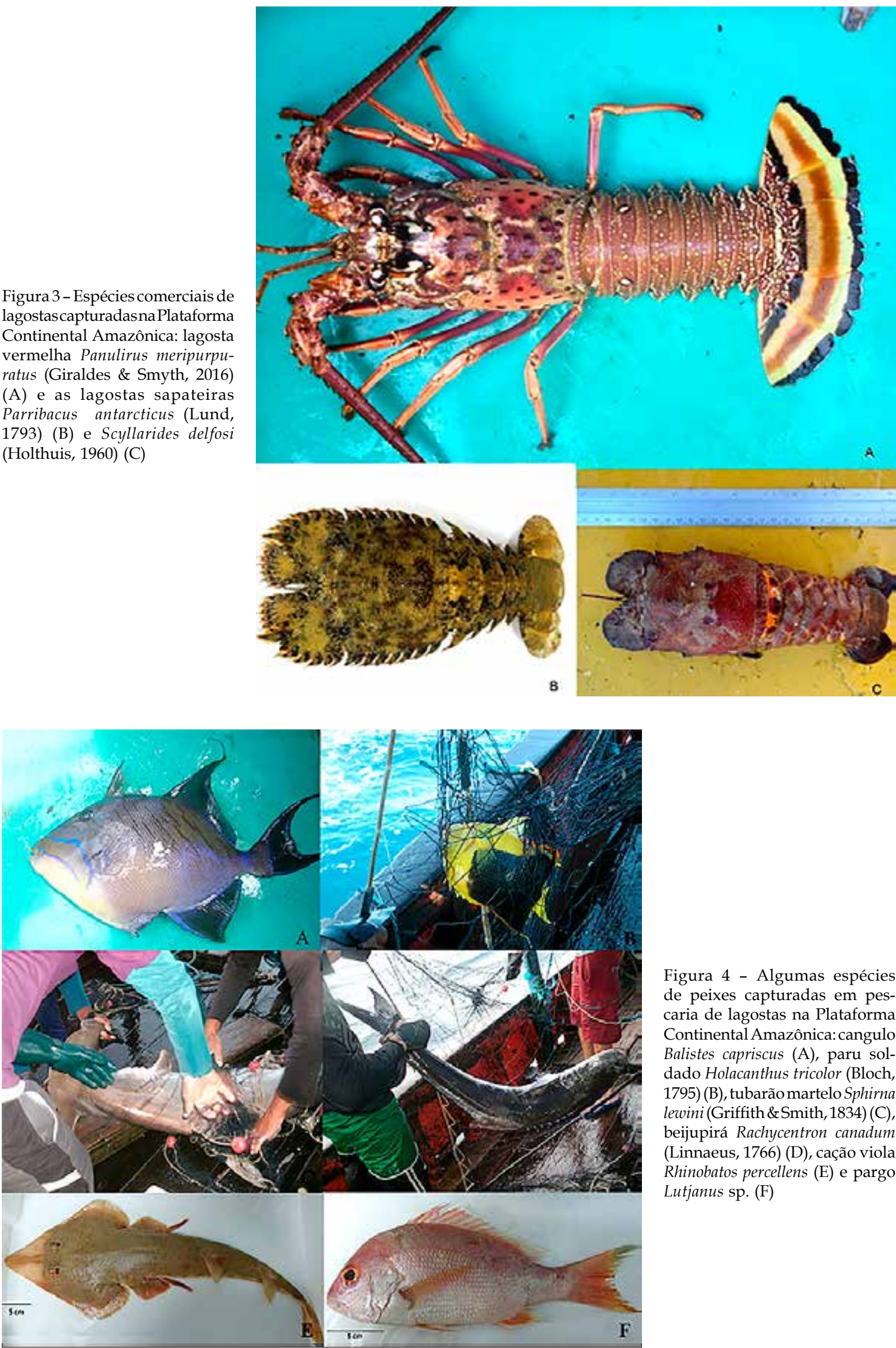

Figura 4 - Algumas espécies de peixes capturadas em pescaria de lagostas na Plataforma Continental Amazônica: cangulo Balistes capriscus (A), paru soldado Holacanthus tricolor (Bloch, 1795) (B), tubarão martelo Sphirna lewini (Griffith \&Smith, 1834) (C) beijupirá Rachycentron canadum (Linnaeus, 1766) (D), cação viola Rhinobatos percellens (E) e pargo Lutjanus sp. (F) 
Figura 5 - Outros organismos aquáticos capturados em pescarias de lagostas na Plataforma Continental Amazônica: ouriço Echinometra lucuter (Linnaeus, 1758). (A), alga (B), estrela-do-mar (C), gastrópodo Turbinella leavigata (Anton, 1838) (D), esponja (E) e caranguejo Calappa ocellata (Holthuis, 1958) (F)

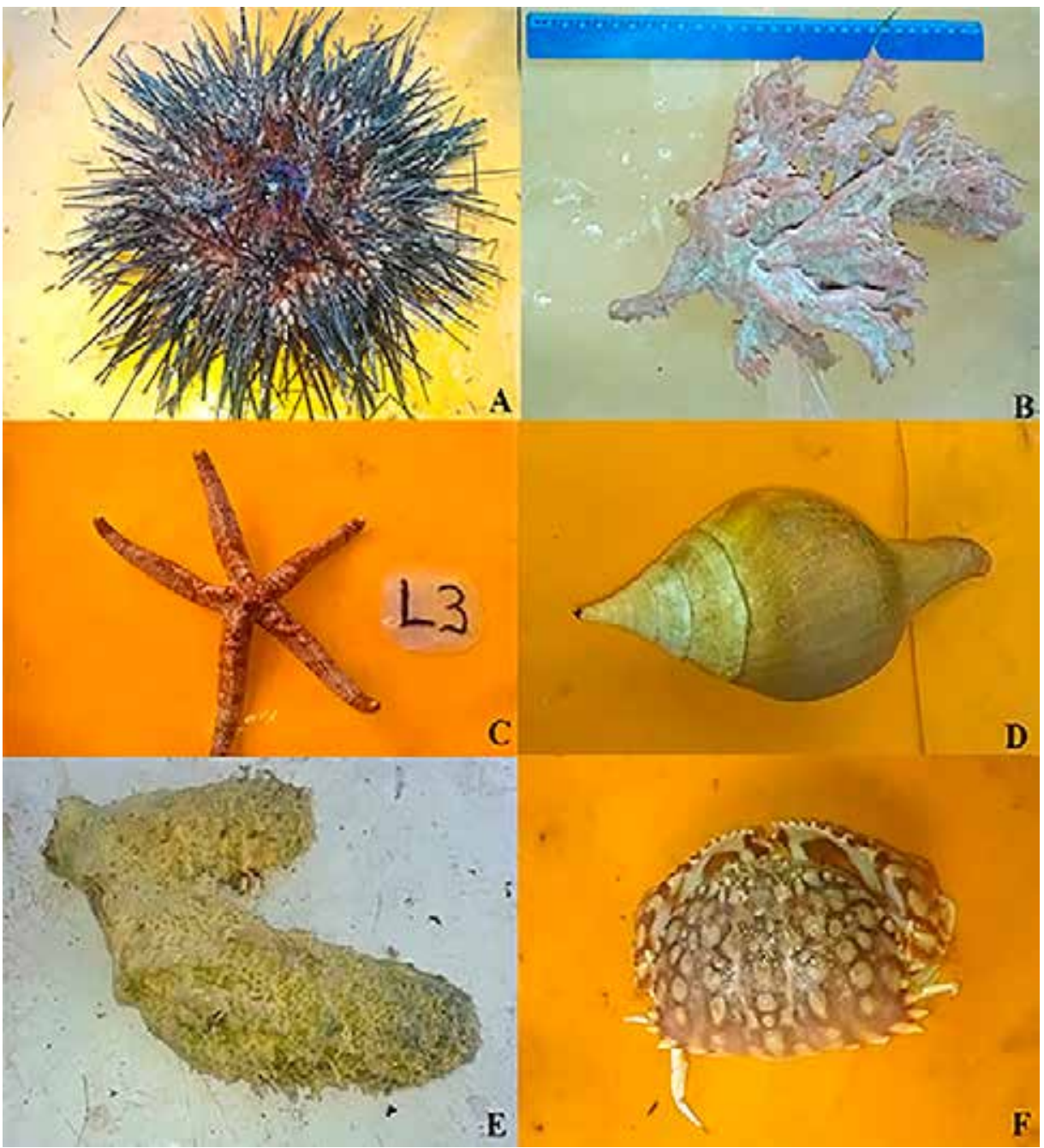

\section{Processamento a bordo}

O processamento a bordo se inicia logo após a rede ser içada. As lagostas capturadas são submetidas a uma lavagem com jato de água e acondicionadas em tambor de PVC (policloreto de vinila), permanecendo nele até o final do recolhimento. Os peixes capturados são acondicionados na urna para fins de comercialização (como cortesia aos pescadores), outros armazenados para serem utilizados como refeição, outros utilizados nas pescarias como iscas e as demais espécies sem interesse são descartadas.

Após a lavagem, ocorre o "descabeçamento" das lagostas, que nada mais é do que a separação da cauda do cefalotórax (Figura 6).

Após a retirada do cefalotórax, as caudas são lavadas novamente e acondicionadas em urnas, em camadas alternadas de gelo e cauda de lagosta. Depois desse processo, os pescadores direcionam seus trabalhos às cabeças das lagostas, de onde retiram a carne localizada nos grandes acúleos, sendo esse subproduto chamado de "pernil de lagosta". As caudas podem ficar acondicionadas de 30 a 40 dias, dependendo do ritmo das pescarias. 
Figura 6 - Pesca de lagostas na Plataforma Continental Amazônica. Lagosta emalhada (A), retirada da lagosta da rede (B), lagosta inteira (C) e caudas e cefalotórax (D)

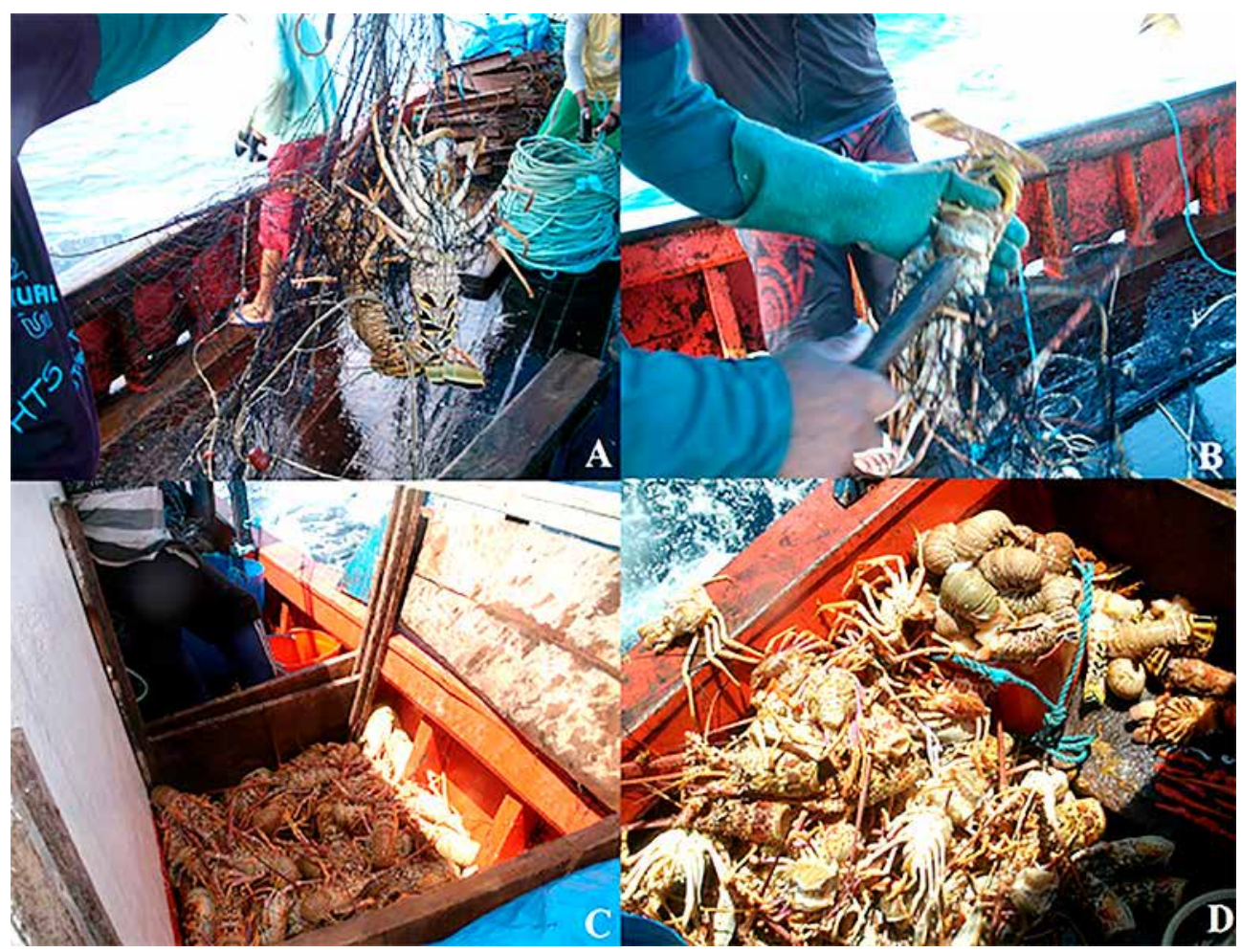

\section{Aspectos legais da pesca}

Com relação à legalidade da pesca da lagosta na região, observando as afirmativas coletadas durante o estudo, o cenário não difere do quadro preocupante existente em outras regiões brasileiras, principalmente quando se considera a complexidade da atividade e sua grande importância no contexto social, econômico e ambiental. Há um significativo contingente de pessoas envolvidas e um grande aporte de infraestrutura e apoio logístico, considerando os municípios paraenses de Bragança e Augusto Corrêa.

Observou-se que existem dificuldades significativas quanto à falta de informações sobre a composição da frota e o número de embarcações licenciadas, à operacionalidade deficitária no monitoramento das mesmas a partir do Programa Nacional de Rastreamento de Embarcações Pesqueiras por Satélite (PREPS) e ao tipo de apetrecho de pesca utilizado na área pesquisada.

Todo o arcabouço legal que regulamenta as áreas de pesca e tamanho mínimo de captura, estabelece o período de defeso e cria um programa de monitoramento das embarcações lagosteiras é real e de amplo conhecimento de todos aqueles que trabalham com a pesca da lagosta, no entanto, há de se observar uma completa ausência de responsabilidades tanto por parte do poder público, quanto do setor produtivo.

\section{DISCUSSÃO}

A pesca da lagosta realizada na Plataforma Continental Amazônica possui um importante papel no desenvolvimento do setor pesqueiro na região Norte. Parte da frota que 
atua na região está sediada nos municípios de Bragança e Augusto Corrêa, importantes portos de desembarque no Pará. No entanto, atuam na mesma área de pesca embarcações lagosteiras pertencentes a outros estados, como Maranhão, Piauí e Ceará. Ivo et al. (2013) ressaltam que a migração de parte da frota para atuar na Plataforma Continental Amazônica se deve à existência de um importante porto pesqueiro, Bragança, no Pará, e à sua função de fornecedora de "capital biológico de reserva" para o Nordeste, sempre que a queda da produção emitia sinais de alerta de que os estoques estavam ameaçados de sobrexploração. Os mesmos autores relatam que a localização das zonas de pesca de lagostas na parte externa da plataforma continental é decorrente da enorme influência do aporte fluvial, que acarreta águas de baixa salinidade.

Porto, Cintra e Silva (2005), analisando dados coletados de 2001 a 2003, descreveram que a pesca da lagosta na costa norte era realizada entre as latitudes $3^{\circ} 50^{\prime} \mathrm{N}$ (Amapá) e $1^{\circ} 30^{\prime} \mathrm{N}$ (Pará). Os dados atuais demonstram que a pesca deslocou-se para mais ao norte; assim, a pesca da lagosta no norte brasileiro é realizada entre as latitudes $4^{\circ} \mathrm{N}, 49^{\circ} 30^{\prime} \mathrm{W}$ (Amapá) e 130’ N (Pará) em profundidades de $60 \mathrm{~m}$ a $98 \mathrm{~m}$. Profissionais envolvidos com a atividade justificam que o deslocamento mais ao norte ocorre devido à procura de novos estoques e por conta de rivalidade com a frota pargueira, pois ambas as frotas disputam a mesma área de pesca.

Atualmente, existe um quantitativo de 43 embarcações atuando na pesca da lagosta. Tais embarcações, em sua totalidade, pertencem à frota artesanal, sendo que a maioria usa a rede caçoeira como apetrecho de pesca, possuindo casco em madeira, medindo entre 12 m e 16 m, com potência de motor variando de 114 a 200 hp. Essas informações atuais reforçam a predominância da atuação desse tipo de embarcação e o referido apetrecho de pesca, corroborando com Porto, Cintra e Silva (2005), quando diziam que durante os anos de 2002 e 2003 haviam registrado apenas embarcações da frota artesanal operando com rede, na área da Plataforma Continental Amazônica.

Com relação às embarcações, não há uma diversidade significativa quanto ao tipo, quando comparadas à frota que atua no Nordeste. Tal fato pode ser explicado pela necessidade do uso de embarcações mais robustas e com significativa autonomia de mar, devido às grandes distâncias de localização dos pontos de pesca aos portos de origem.

Observou-se a predominância de embarcações motorizadas, também denominadas de lanchas motorizadas, reforçando a afirmativa de Ivo et al. (2013), que a frota atuante na região é composta apenas por barcos motorizados, representados pelas lanchas, com motor de 106 hp, 6 cilindros, casco de madeira, autonomia de mar de 30 dias, equipamentos auxiliares de navegação, guinchos mecânico e hidráulico para recolhimento dos apetrechos e armazenagem do pescado em urnas frigoríficas para resfriamento com gelo.

Existem importantes fatores que reforçam a predominância desse tipo de embarcação. Vários autores relatam que, devido à baixa produtividade das pescarias e à insuficiente rentabilidade, os barcos industriais foram gradativamente sendo paralisados e hoje a frota é composta basicamente por barcos de madeira, com comprimento variando geralmente entre 12 m e 16 m, denominadas "lanchas" (Fonteles-Filho et al., 1985; Carvalho et al., 1996; Castro-Silva \& Rocha, 1999).

Um fator importante a respeito das embarcações atuantes na área é sua "universalização" de atuação, uma vez que elas podem ser adaptadas para atuar em pescarias de outras espécies de recursos pesqueiros, como o pargo Lutjanus purpureus (Poey, 1866), a pescada amarela Cynoscion acoupa (Lacepède, 1801), a gurijuba Aspistor luniscutis Valenciennes, 1840, entre outras. 
Nas pescarias acompanhadas, observou-se a predominância do uso da rede caçoeira, como apetrecho de pesca. Apesar da proibição do uso do referido apetrecho, a partir da IN 138/06 (Brasil, 2006), observa-se a sua larga utilização. Alguns fatores podem ser indicados não como justificativas, mas sim como consequências, que, segundo opiniões apontadas, refletem tanto a fragilidade da atuação das instituições governamentais, quanto a falta de conscientização do setor produtivo.

Quanto ao tipo de rede utilizada na Plataforma Continental Amazônica, as embarcações usam redes com panagem multifilamento trançado, sem nó, sendo a preferida dos mestres e pescadores por serem mais resistentes, adequando-se à profundidade trabalhada, ao tipo de substrato existente e ao manuseio a bordo.

Lima e Melo (2013) relatam que o uso da rede é bastante difundido na pescaria da lagosta e que a proibição se deve pelo pretexto de capturar a lagosta abaixo do tamanho mínimo permitido para a comercialização e pelo revolvimento e recolhimento de sedimentos do fundo do mar, sedimentos esses importantes para a sobrevivência de crustáceos de diversas outras espécies marinhas.

A partir de informações fornecidas por empresa sediada no município de Bragança, atuante na regularização de embarcações pesqueiras e em sistemas de rastreamento, é difícil afirmar com exatidão o quantitativo real de embarcações na atividade, bem como a situação de permissão das mesmas. Aragão (2010) ressalta que pouca atenção tem sido dispensada ao monitoramento da atividade e a estudos e avaliações sobre o nível de explotação dos estoques de lagosta. O mesmo autor também comenta que a composição da frota, bem como o número de barcos efetivamente operando hoje, é desconhecida.

Lima, Mendes e Silva (2014) ressaltam que a maior parte da frota lagosteira que opera no estado do Pará não possui licença e se apresenta em estado precário de conservação. A fiscalização dos barcos que operam na região é precária e também não há controle sobre o tamanho mínimo de captura, que, para as espécies Panulirus meripurpuratus e Panulirus laevicauda, é de 13 e $11 \mathrm{~cm}$ respectivamente para o tamanho da cauda.

O Ibama (2008) ressalta que, apesar da existência de um Plano de Gestão para o Uso Sustentável de Lagostas no Brasil, elaborado sob a coordenação do Ibama e aprovado pelo Comitê de Gestão do Uso Sustentável de Lagostas (CGSL), integrado por instâncias do Governo e da sociedade civil diretamente relacionadas ao tema, a atividade continua sendo exercida por meio de padrões de pesca predatórios e de forma majoritariamente ilegal.

Aragão (2010) cita como agravantes nesse contexto os subsídios e outros tipos de benefícios oferecidos pelo Governo, tendo como exemplos o subsídio do óleo diesel e o seguro defeso, onde tais fatores contribuem de forma efetiva para a manutenção da forte pressão de pesca sobre os estoques.

Com relação à diversidade nas capturas, foi observada a ocorrência de 28 espécies de peixes e três espécies de lagostas. A diversidade de espécies capturadas nas pescarias de lagosta é historicamente grande. Já na década de 1960 aparecem registros de que na pesca com manzuás (tipo de covo rudimentar), na costa do Ceará, ocorriam 32 espécies de peixes, 26 de moluscos e 11 de crustáceos (Fausto-Filho; Matthews \& Lima, 1966).

Na década de 1990, ao estudar as pescarias de lagosta com covos e caçoeiras realizadas no Ceará, Ivo, Santiago e Monteiro-Neto (1996) encontraram 54 espécies, sendo 44 de peixes e 10 de crustáceos. Rocha et al. (1997), analisando a fauna acompanhante oriunda de covo e rede de emalhar ao largo das costas do Maranhão, do Ceará e do Rio Grande do Norte, encontraram uma riqueza de espécies ainda maior (91), embora a área de amostragem tenha sido bem mais ampla, tendo sido explorados diferentes ambientes e faixas de 
profundidade. Já no caso do litoral de Pernambuco, há o registro de pelo menos 41 espécies de peixes na pesca de saramunete, que tem área de atuação similar à da pesca de lagosta com covo (Marques \& Ferreira, 2010).

Considerando a significativa ocorrência de outras espécies, Broadhurst e Kennelly (1996) propõem quantificar os descartes, identificar as principais espécies envolvidas, efetuar modificações que minimizem a mortalidade, desenvolver tecnologias que diminuam as capturas e desenvolver estratégias de aproveitamento das mesmas. Em países desenvolvidos, e com grande demanda de proteína animal, já existem medidas para o aproveitamento dessa fauna acompanhante (Vendeville, 1991).

No Brasil e em outros países subdesenvolvidos, estudos sobre esses "rejeitos" ainda são escassos, situação esta que embasa a inexistência total de políticas de gestão ambiental para o seu aproveitamento, o que agrava os atuais sinais de esgotamento de vários recursos marinhos (Alverson et al., 1994; Vianna; Tomás \& Verani, 2000).

Na pesquisa realizada, observou-se a falta de higienização das estruturas e o inadequado manuseio das lagostas a bordo das embarcações. Segundo Cardonha e Vieira (1979), a qualidade sanitária da lagosta reflete as condições higiênicas dos barcos pesqueiros e o excessivo manuseio durante as fases de processamento, desde a captura até o congelamento, resultando em um produto de qualidade sanitária duvidosa, que, no caso de exportação, a lagosta pode ter o seu valor comercial reduzido (Cardonha \& Vieira, 1979). Santos et al. (2008) ressaltam que práticas artesanais e industriais inadequadas de preservação e processamento dão como resultado produtos de qualidade inferior e/ou deteriorados.

Agradecimentos - Ao Instituto Chico Mendes de Conservação da Biodiversidade e ao Instituto Brasileiro de Meio Ambiente e Recursos Naturais Renováveis, pelos dados, e à Universidade Federal Rural da Amazônia, pelo apoio técnico. Aos amigos técnicos, armadores, mestres e pescadores que trabalham no setor lagosteiro dos municípios de Bragança e Augusto Corrêa, pela cooperação e atenção disponibilizada durante a realização da pesquisa.

\section{REFERÊNCIAS BIBLIOGRÁFICAS}

Alverson, D.L.; Freeberg, M.H.; Murawski, S.A. \& Pope, J.G. A global assessment of fisheries by-catch and discards. FAO Fisheries Technical Paper, n. 339, 233 p., 1994.

Aragão, J.A.N. Pesca de lagostas no Brasil: monitorar para ordenar. Bol. Téc. Cient. Cepene, Tamandaré, v. 18, n. 1, p. 49-60, 2010.

Aragão, J.A.N. \& Cintra, I.H.A. Avaliação do estoque de lagosta vermelha Panulirus argus na costa brasileira. Arq. Ciên. Mar, Fortaleza, v. 51, n. 2, p. 7-26, 2018.

Brasil. Instrução Normativa Ibama $n^{\circ} 138$, de 6 de dezembro de 2006. Dispõe sobre os comprimentos mínimos das lagostas Panulirus argus e $P$. laevicauda e dá outras providências. Diário Oficial da União, Poder Executivo, Brasília, DF, 7 dez. 2006.

Brasil. Ministério do Desenvolvimento, Indústria e Comércio Exterior - MDIC (Sistema AliceWeb), 2012. Disponível em: http://aliceweb.desenvolvimento.gov.br/. Acesso em: 16 abr. 2013.

Broadhurst, M.K. \& Kennelly, S.J. Effects of the circumference of codends and a new design of squaremesh panel in reducing unwanted bycatch in the New South Wales oceanic prawn-trawl fishery. Fish. Res., v. 27, n. 4, p. 203-214, 1996. 
Cardonha, A.M.S. \& Vieira, R.H.S.F. Estudos bacteriológicos da lagosta nas diversas fases de processamento. Arq. Ciên. Mar, Fortaleza, v. 19, n. 1/2, p. 81-85, 1979.

Carvalho, R.C.A., Ferreira, C.R.C., Vasconcelos, J.A., Oliveira, M.Y.S. \& Campos, L.M.A. Custo e rentabilidade de embarcações envolvidas na pesca da lagosta no Nordeste do Brasil. 1995. Bol. Téc. Cient. Cepene, Tamandaré, v. 4, n. 1, p. 233-262, 1996.

Castro-Silva, S.M.M. \& Rocha, C.A.S. Embarcações, aparelhos e métodos de pesca utilizados nas pescarias de lagosta no estado do Ceará. Arq. Ciên. Mar, Fortaleza, v. 32, n. 1/2, p. 1-21, 1999.

Cervigón, F.; Cipriani, R.; Fisher, W.; Garibaldi, M.; Hendrickx, M.; Lemus, A.J.; Márquez, R.; Poutiers, J.M.; Robaina, G. \& Rodriguez, B. Guia de campo de las espécies comerciales marinas y de águas salobras de la costa septentrional de Sur América. Roma, FAO, 513 p., 1992.

Fausto-Filho, J.; Matthews, H.R. \& Lima, H.H. Nota preliminar sobre a fauna dos bancos de lagostas no Ceará. Arq. Ciên. Mar, Fortaleza, v. 6, n. 2, p. 127-130, 1966.

Figueiredo, J.L. \& Menezes, N.A. Manual de peixes marinhos do Sudeste do Brasil, 2. Museu de Zoologia, Universidade de São Paulo, São Paulo, 300 p.,1979.

Figueiredo, J.L. \& Menezes, N.A. Manual de peixes marinhos do Sudeste do Brasil, 4. Museu de Zoologia, Universidade de São Paulo, São Paulo, 105 p., 1980.

Figueiredo, J.L. \& Menezes, N.A. Manual de peixes marinhos do Sudeste do Brasil, 6. Museu de Zoologia, Universidade de São Paulo, São Paulo, 116 p., 2000.

Floriani, D.C.; Fukuda, J.C. \& Pinto, E.F. Parque Nacional dos Lençois Maranheses: o maior campo de dunas costeiras da América do Sul. Rev. Gest. Cost. Integ., v. 1, n. 1, p. 62-64, 2004.

Fonteles-Filho, A.A.; Souza, A.R.; Coelho, A.S. \& Ximenes, M.O.C. Parâmetros técnicos e índices de rendimento da frota lagosteira do estado do Ceará, Brasil. Arq. Ciên. Mar, Fortaleza, v. 24, n. 1, p. 89-100, 1985.

Giraldes, B.W. \& Smyth, D.M. Recognizing Panulirus meripurpuratus sp. nov. (Decapoda: Palinuridae) in Brazil - Systematic and biogeographic overview of Panulirus species in the Atlantic Ocean. Zootaxa, v. 4107, n. 3, p. 353-366, 2016.

Ibama. Plano de gestão para o uso sustentável de lagostas no Brasil: Panulirus argus (Latreille, 1804) e Panulirus laevicauda (Latreille, 1817). Ibama, Brasília, 121 p., 2008.

Ivo, C.T.C.; Santiago, M.E. \& Monteiro-Neto, C. Fauna acompanhante na pesca das lagostas Panulirus argus (Latreille) e Panulirus laevicauda (Latreille) no estado do Ceará, Brasil. Arq. Ciên. Mar, Fortaleza, v. 30, n. 1/2, p. 41-47, 1996.

Ivo, C.T.C.; Fonteles-Filho, A.A.; Silva, A.C. \& Vieira, R.H.S.F. Cadeia produtiva da lagosta nas regiões Norte e Nordeste do Brasil. RDS Editora, Fortaleza, 216 p., 2013.

Lima, E.H.S. \& Melo, M.T.D. Levantamento das principais artes de pesca utilizadas nas comunidades pesqueiras na área de atuação do projeto Tamar-ICMBio. Regional Ceará, Ceará, 47 p., 2013.

Lima, W.M.G.; Mendes, N.C.B. \& Silva, B.B. Estudo da produção pesqueira e fecundidade de lagostas no Norte do Brasil, municípios de Bragança e Augusto Corrêa - PA, Biota Amaz., v. 4, n. 3, p. 48-56, 2014.

Marques, S. \& Ferreira, B.P. Composição e características da pesca de armadilhas no litoral norte de Pernambuco - Brasil. Bol. Téc. Cient. Cepene, Tamandaré, v. 18, n. 1, p. 49-60, 2010. 
Nittrouer, C.A.; Kuehl, S.A.; Sternberg, R.W.; Figueredo-Júnior, A.G. \& Faria-Júnior, L.E. An introduction to the geological significance of sediment transport and acumulation on the Amazon Continental Shelf. Mar. Geol., v. 125, n. 3/4, p. 177-192, 1995.

Oliveira, G.M. A pesca de lagostas, in Oliveira, G.M. (org.). Pesca e aquicultura no Brasil, 1991-2000: produção e balança comercial. Ibama, Brasília, 259 p., 2005.

Porto, V.M.S.; Cintra, I.H.A. \& Silva, K.C.A. Sobre a pesca da lagosta vermelha, Panulirus argus (Latreille, 1804) na região Norte do Brasil. Bol. Téc. Cient. Cepnor, Belém, v. 5, n. 1, p. 83-92, 2005.

Rocha, C.A.; Franklin-Júnior, W.; Dantas, N.P.; Farias, M.F. \& Oliveira, A.M.E. Fauna e flora acompanhantes da pesca da lagosta no Nordeste do Brasil. Bol. Téc. Cient. Cepene, Tamandaré, v. 5, n. 1, p. 11-22, 1997.

Santos, T.M.; Martins, R.T.; Santos, W.L.M. \& Martins, N.E. Inspeção visual e avaliações bacteriológica e físico-química da carne de piramutaba (Brachyplatistoma vaillanti) congelada. Arq. Bras. Med. Vet. Zootec., Belo Horizonte, v. 60, n. 6, p. 1538-1545, 2008.

Silva, K.C.A.; Cruz, R.; Cintra, I.H.A. \& Abrunhosa, F.A. Structure and diversity of the lobster community on the Amazon Continental Shelf. Crustaceana, v. 86, n. 9, p. 10841102, 2013.

Silva, K.C.A.; Fransen, C.H.J.M.; Ramos-Porto, M.; Paiva, K.S.; Cintra, I.H.A. \& Cruz, R. Report of Scyllarus chacei Holthuis, 1960 (Decapoda, Scyllaridae) in Amapá state continental shelf of Brazil. Crustaceana, v. 85, n. 10, p. 1171-1177, 2012.

Vendeville, D. Tropical shrimp fisheries: types of fishing gears used and their selectivity. FAO Fisheries Technical Paper, 75 p., 1991.

Vianna, M.; Tomás, A.R.G. \& Verani, J.R. Aspects of the biology of the atlantic midshipman, Porichthys porosissimus (Teleostei, Batrachoididae): an important by-catch species of shrimp trawling off southern Brazil. Rev. Bras. Oceanogr., v. 48, n. 2, p. 133-142, 2000. 